\title{
Intracavity suction and drainage in the treatment of emphysematous bullae
}

\author{
A. M. MACARTHUR AND S. W. FOUNTAIN \\ From King's College Hospital, London, UK
}

Macarthur, A. M. and Fountain, S. W. (1977). Thorax, 32, 668-672. Intracavity suction and drainage in the treatment of emphysematous bullae. Patients with large intrapulmonary emphysematous bullae present a considerable therapeutic problem, particularly if their respiratory reserve is low, because of the risks of open operation. The method of draining intrapulmonary cavities, pioneered by Monaldi for the treatment of tuberculosis, is here described as applied to emphysematous bullae.

Thirty-one patients were treated by intracavity suction and drainage. There were two operative deaths $(6 \cdot 5 \%)$. Apart from infection, no other significant postoperative complications ensued. Radiographic improvement occurred in all patients but one $(96.7 \%)$. Where forced expiratory volume in one second and vital capacity were measured improvement was obtained in five out of six patients. Symptomatic improvement, which generally corresponded well to improvement in respiratory function tests, occurred in 28 patients $(90.3 \%)$, all but one of whom survived.

A wide variety of surgical procedures has been advocated for the treatment of emphysematous bullae. The use of plication (Benfield et al., 1966; Fitzgerald et al., 1974), local excision (Wesley et al., 1972), segmental resection (Head et al., 1960), lobectomy (Woo-Ming et al., 1963), and even lung transplantation (Veith et al., 1973) has been reported, with variable results, but mortality from these procedures in some groups is high (HughJones et al., 1966; Belcher, 1974).

The predictive value of preoperative respiratory function tests, however sophisticated, remains in doubt and thus the criteria on which case selection for surgery is based are not universally established (Knudson and Gaensler, 1965).

Intracavity suction and drainage was originally described by Monaldi (1938, 1947), its purpose being to relieve tension in a tuberculous cavity. The method was first used in the treatment of emphysematous bullae in 1946, by John Alexander (personal communication, 1950), and was later more widely adopted (Head and Avery, 1949).

\section{Patients}

The patients were treated at three hospitals. The first operation was in 1952, and the majority of operations have been performed by one of the authors (AMM). All the patients were longstanding sufferers from chronic bronchitis and emphysema, who had undergone prolonged medical treatment. They all had radiographic evidence of substantial intrapulmonary emphysematous cysts and were considered unfit for thoracotomy because of their poor respiratory function. Twenty-eight men and three women were treated.

\section{Procedure}

A two-stage procedure (Head, 1946) was designed to avoid the risk of pneumothorax and entailed the creation of pleural adhesions over the cyst wall by the insertion of an iodine pack extrapleurally at the first stage, and drainage of the cyst three weeks later. This technique was employed initially in this series, but a one-stage procedure is now used.

Using postero-anterior and lateral chest radiographs, the bulla is located, and a suitably placed rib overlying its centre is selected. Through either a vertical or horizontal skin incision, a $2.5 \mathrm{~cm}$ section of rib is excised subperiosteally. A pursestring suture of chromic catgut is inserted in the parietal pleura, picking up the visceral pleura and 
underlying cyst wall. Pleura and cyst wall are then opened within the pursestring, a digital or instrumental check is made that a substantial cavity has been entered, and a large (30F) self-retaining Foley urethral catheter is inserted into the cavity. The retaining balloon is then inflated with air, the pursestring is tightened around its neck, and the catheter is attached to underwater seal drainage, 5-10 $\mathrm{mmHg}$ suction being applied to the open end.

Suction is maintained for $36-48$ hours using a Barrett pump and the catheter remains on underwater seal drainage for 21 days. No difficulty in keeping the tube patent has been experienced. After this the tube is removed and a dry dressing is applied to the drainage wound site. The multiple small bronchiolar leaks close during this time as a result of the inevitable secondary infection

Table 1 Results 1952-66

\begin{tabular}{lll}
\hline & Patients & \\
\cline { 2 - 3 } Result & Number & Percentage \\
\hline Unilateral operation & 19 & 82 \\
Bilateral operation & 4 & 17 \\
Operative death & 1 & $4 \cdot 3$ \\
Recurrence of bulla & 5 & 21 \\
Immediate symptomatic improvement & 19 & 82 \\
Improvement maintained at two years & 12 & 52 \\
\hline
\end{tabular}

associated with the prolonged period of indwelling catheter drainage.

\section{Results}

Two patients died in the postoperative period. Both died of bronchopneumonia after prolonged air leakage. The more recent of these (TA, Table 2) was the only patient whose postoperative radiographs did not show disappearance of the bulla.

The early results, covering the period 1952-66, are summarised in Table 1 . All these operations were performed in two stages, 19 for a unilateral and four for bilateral bullae.

More recently, extensive pre- and postoperative respiratory function testing has been performed, the details of which are documented elsewhere (Pride et al., 1970; 1973). Among those tests most closely related to observed symptomatic improvement are $\mathrm{FEV}_{1}$ and VC, which are recorded in Table 2. Postoperative testing is routinely carried out at three months. One patient (HW, Table 2), symptomatically improved on discharge from hospital, has been lost to follow-up.

In Table 3, percentage postoperative increase in respiratory function is compared with radiographic and symptomatic improvement.

Figures 1 and 2 illustrate the optimum result obtainable.

Table 2 Recent cases: respiratory function tests

\begin{tabular}{|c|c|c|c|c|c|c|}
\hline \multirow[t]{2}{*}{ Patient } & \multirow[t]{2}{*}{ Sex } & \multicolumn{2}{|c|}{$F E V_{1}$ (litres) } & \multicolumn{2}{|c|}{$V C$ (litres) } & \multirow[t]{2}{*}{ No. of stages } \\
\hline & & Preop. & Postop. & Preop. & Postop. & \\
\hline $\begin{array}{l}\text { NP } \\
\text { LB } \\
\text { RB } \\
\text { WR } \\
\text { GG } \\
\text { TA } \\
\text { HW } \\
\text { SB }\end{array}$ & $\begin{array}{l}\mathbf{M} \\
\mathbf{M} \\
\mathbf{M} \\
\mathbf{M} \\
\mathbf{M} \\
\mathbf{F} \\
\mathbf{M} \\
\mathbf{M}\end{array}$ & $\begin{array}{l}1.2 \\
1.0 \\
0.8 \\
0.8 \\
0.6 \\
0.5 \\
0.5 \\
0.9\end{array}$ & $\begin{array}{l}0.7 \\
1.1 \\
1.4 \\
1.2 \\
0.9 \\
- \\
- \\
0.9\end{array}$ & $\begin{array}{l}3 \cdot 5 \\
2 \cdot 8 \\
1 \cdot 4 \\
2 \cdot 0 \\
1 \cdot 7 \\
1 \cdot 8 \\
1 \cdot 6 \\
2 \cdot 5\end{array}$ & $\begin{array}{l}2 \cdot 0 \\
3 \cdot 3 \\
2 \cdot 9 \\
3 \cdot 1 \\
2 \cdot 2 \\
- \\
-\end{array}$ & $\begin{array}{r}1 \\
1 \\
1 \\
2+1 \\
1 \\
1 \\
2 \\
1\end{array}$ \\
\hline
\end{tabular}

Table 3 Recent cases: changes in respiratory function compared with radiographic and symptomatic improvement

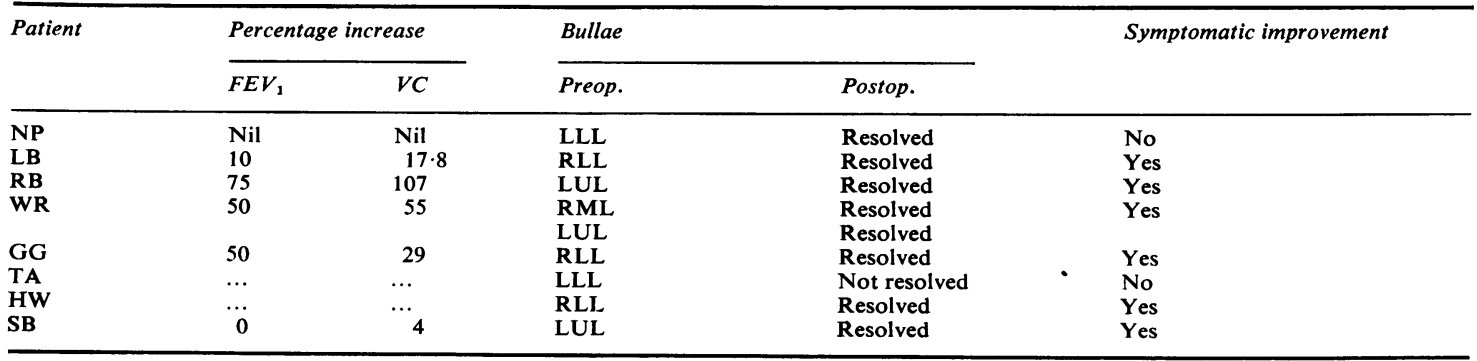

LLL = left lower lobe; RLL = right lower lobe; $R M L=$ right middle lobe; $L U L=$ left upper lobe. 


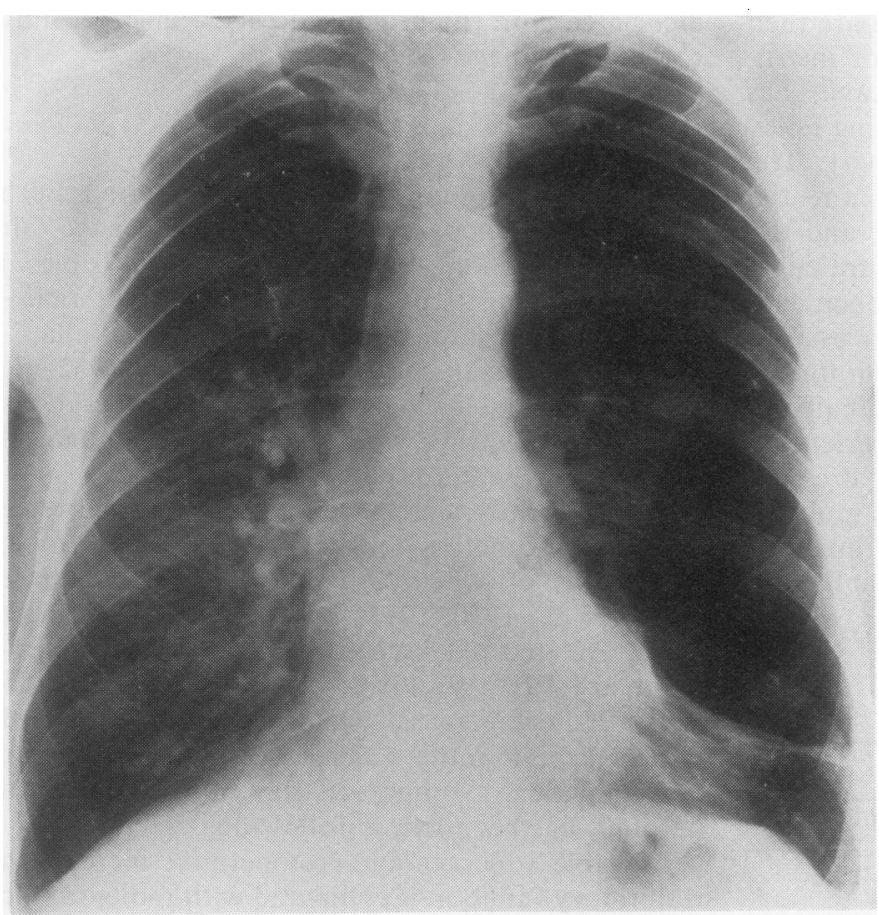

Fig. 1 ( $R B$, Table 2) Preoperative chest radiograph showing left upper lobe bulla.

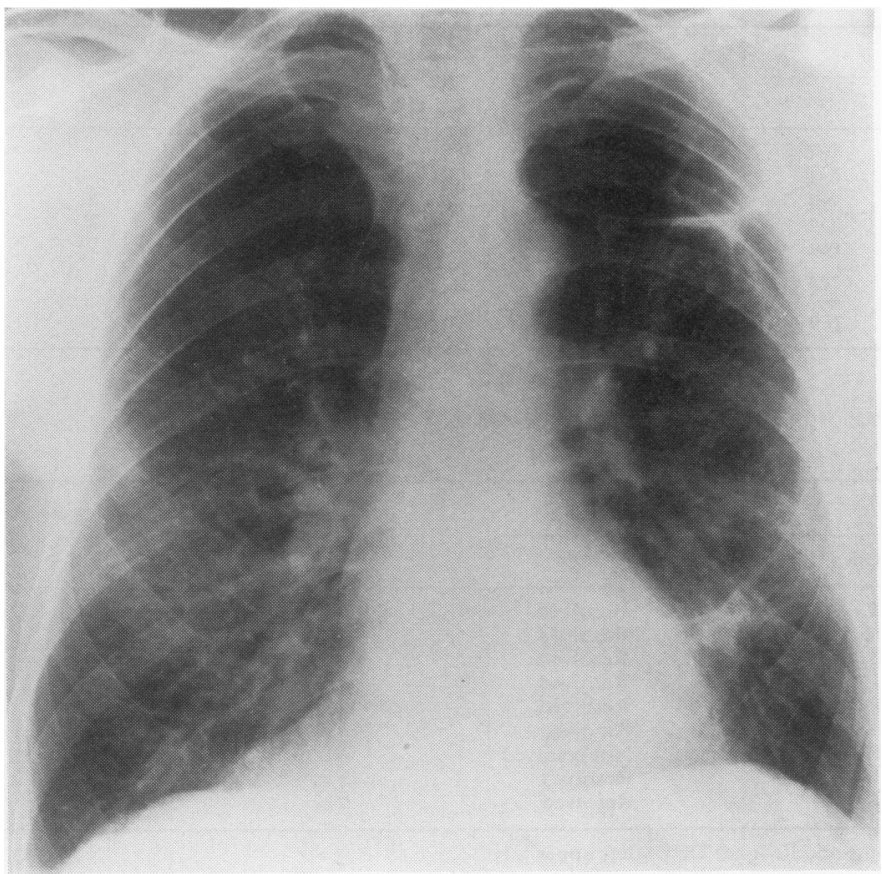

Fig. 2 (RB, Table 2) Chest radiograph three months after operation, showing resolution of bulla.

\section{오}




\section{Discussion}

The purpose of surgical treatment for areas of bullous emphysema is twofold. First, if the bulla is ventilated, it merely contributes to the physiological dead space, since the attenuated or destroyed alveoli within it are invariably unperfused (Pride et al., 1970). Second, and more important, even if the bulla is relatively unventilated, as it enlarges it not only destroys surrounding lung tissue but also compresses potentially functioning lung. Removal of the bulla thus permits expansion of collapsed alveoli, decreases airway resistance, and increases dynamic compliance (Rogers et al., 1968).

The principal indication for surgery, therefore, is the demonstration of a single large bulla with evidence of surrounding lung compression, the vanishing lung syndrome (Ray et al., 1976). Sung et al. (1973) suggest that one-third of the lung field should be involved for surgery to be of value. The importance of these two concomitant factors has been stressed (Wesley et al., 1972), and in this and other series less good results have been obtained in patients with multiple small cysts. As might be expected, the results of operating on patients with diffuse, non-bullous emphysema were not encouraging (Brantigan et al., 1959; Head et al., 1960).

The use of tests of whole lung and regional respiratory function, both to predict the value of surgery and to assess its results, is described in detail elsewhere (Pride et al., 1970, 1973). Correlation with symptomatic improvement has been variable, but forced expired volume in one second and vital capacity have been the respiratory function tests found most closely to correlate with the clinical results. It is still not possible, however, to predict quantitatively which patients will benefit from surgery, and, in conjunction with radiographic evidence of both bulla size and surrounding lung compression, reliance must be placed principally on symptoms (Belcher, 1974; Ray et al., 1976).

Although good results have been obtained from a number of operative procedures, formal thoracotomy has a high mortality rate in patients with poor respiratory reserve (Brantigan et al., 1959; Hugh-Jones et al., 1966; Belcher, 1974). Lobectomy, in particular, has been criticised on the grounds that it involves the resection of functioning as well as non-functioning tissue (Knudson and Gaensler, 1965). Plication may be time-consuming, and prolonged intercostal drainage may in any case be required to deal with persistent air leaks after procedures involving formal thoracotomy
(Fitzgerald et al., 1974). Although this may represent no more than an inconvenience to the patient, the situation occasionally arises where a persisient pneumothorax embarrasses respiratory function sufficiently to necessitate artificial ventilation. A vicious circle is then set up whereby the ventilatory pressure required keeps the air leak patent, preventing absorption of the pneumothorax, and a significant proportion of the tidal volume passes out through the intercostal drain.

It is suggested, therefore, that intracavity suction and drainage represents a simple, safe, speedy, and effective treatment of emphysematous bullae in patients considered to be a bad risk for formal thoracotomy.

We are grateful to Dr. P. Hugh-Jones and the staff of the Chest Unit at King's College Hospital for their help in the preparation of this paper and for the performance of pre- and postoperative respiratory function tests.

\section{References}

Belcher, J. R. (1974). Bullous cysts of the lung. In Surgery of the Lung, edited by R. E. Smith and W. G. Williams, pp. 219-236. Butterworths, London. Benfield, J. R., Cree, E. M., Pellett, J. R., Barbee, R., Mendenhall, J. T., and Hickey, R. C. (1966). Current approach to the surgical management of emphysema. Archives of Surgery, 93, 59-70.

Brantigan, O. C., Mueller, E., and Kress, M. B. (1959). A surgical approach to emphysema. American Review of Respiratory Diseases, Supplement (July), 80, 194-206.

Fitzgerald, M. X., Keelan, P. J., Cugell, D. W., and Gaensler, E. A. (1974). Long-term results of surgery for bullous emphysema. Journal of Thoracic and Cardiovascular Surgery, 68, 566-587.

Head, J. M., Head, L. R., Hudson, T. R., and Head, J. R. (1960). The surgical treatment of emphysematous blebs and localised vesicular and bullous emphysema: analysis of 50 cases. Journal of Thoracic and Cardiovascular Surgery, 40, 443-460.

Head, J. R. (1946). Intracavitary (Monaldi) suction. Journal of Thoracic Surgery, 15, 153-161.

Head, J. R., and Avery, E. E. (1949). Intracavity suction (Monaldi) in the treatment of emphysematous bullae and blebs. Journal of Thoracic Surgery, 18, 761-776.

Hugh-Jones, P.. Ritchie, B. C., and Dollery, C. T. (1966). Surgical treatment of emphysema. British Medical Journal, 1, 1133-1138.

Knudson, R. J., and Gaensler, E. A. (1965). Surgery for emphysema. Annals of Thoracic Surgery, 1, 332-362.

Monaldi, V. (1938). Tentativi di aspirazione endocavitaria nelle caverne tubercolari del pulmone. Lotta contro la Tubercolosi, 9, 910-911. 
Monaldi, V. (1947). Endocavitary aspiration: its practical applications. Tubercle, 28, 223-228.

Pride, N. B., Barter, C. E., and Hugh-Jones, P. (1973). The ventilation of bullae and the effect of their removal on thoracic gas volumes and tests of overall pulmonary function. American Review of Respiratory Diseases, 107, 83-98.

Pride, N. B., Hugh-Jones, P., O'Brien, E. N., and Smith, L. A. (1970). Changes in lung function following surgical treatment of bullous emphysema. Quarterly Journal of Medicine, 39, 49-69.

Ray, J. F., III, Lawton, B. R., Smullen, W. A., Myers, W. O. and Saulter R. D. (1976). Effective surgical palliation of giant compressive bullous emphysema (vanishing lung syndrome): long-term follow-up. American Surgeon, 42, 181-185.

Rogers, R. M., DuBois, A. B., and Blakemore, W. S. (1968). Effect of removal of bullae on airway conductance and conductance volume ratios. Journal of Clinical Investigation, 47, 2569-2579.

Sung, D. T., Payne, W. S., and Black, L. F. (1973). Surgical management of giant bullae associated with obstructive airway disease. Surgical Clinics of North America, 53, 913-920.

Veith, F. J., Koerner, S. K., Siegelman, S. S., Torres, M., Bardfeld, P. A. Attai, L. A., Boley, S. J., \& Takaro, T., and Gliedman M. L. (1973). Single lung transplantation in experiment and human emphysema. Annals of Surgery, 178, 463-476.

Wesley, J. R., Macleod, W. M., and Mullard, K. S. (1972). Evaluation and surgery of bullous emphysema. Journal of Thoracic and Cardiovascular Surgery, 63, 945-955.

Woo-Ming, M., Capel, L. H., and Belcher, J. R. (1963). The results of surgical treatment of large air cysts of the lung. British Journal of Diseases of the Chest, 57, 79-85.

Requests for reprints to: S. W. Fountain, FRCS, Dulwich Hospital, East Dulwich Grove, London SE22 8PT, UK. 